\title{
Avaliação de conformidade da agricultura do Caparaó Capixaba nos processos de produção integrada visando a certificação de café
}

\section{Conformity valuation of agriculture in Caparaó Capixaba regarding integrated production processes aiming coffee certification}

\author{
Jorge Araújo Santos ${ }^{1}$; João Batista Pavesi Simão ${ }^{2}$
}

\begin{abstract}
Resumo - A certificação de café têm como intuito inserir a produção de café no conceito de desenvolvimento sustentável, proporcionando vantagens a respeito dos ecossistemas, proteção do solo, racionalidade no uso de insumos, melhor utilização da água e melhoria na qualidade de vida das pessoas envolvidas, além da valorização da produção e do produto, com maior retorno econômico e mais responsabilidade social. As certificações contêm regras e normas que são reconhecidas mundialmente e desta forma, contribuindo significativamente na organização interna e nas melhorias socioambientais das propriedades. Além disso, auxilia na promoção de avanços nas regiões cafeeiras, favorecendo uma maior sustentabilidade ambiental e valorização da cafeicultura nacional. O objetivo deste trabalho foi analisar o nível de conformidade de agricultores de municípios da microrregião política denominada Caparaó Capixaba, no Espírito Santo, nos processos de certificação. Para a coleta de dados, adotou-se uma abordagem com a aplicação de questionário, contendo 103 questões, relacionando itens como rastreabilidade, variedades, gerenciamento da propriedade, gestão e uso do solo, emprego de fertilizantes, proteção fitossanitária das plantas, irrigação, colheita e pós-colheita, gestão e resíduos da propriedade, bem estar saúde e segurança de trabalhadores, conservação do meio ambiente e gestão administrativo-financeira. Os resultados trazem a média de cada item abordado e apontaram que os cafeicultores familiares e suas propriedades na região do Caparaó Capixaba apresentam, de modo geral, baixo nível de conformidade nos processos de produção integrada visando certificação de café.
\end{abstract}

Palavras-chave: Sustentabilidade socioambiental; Cafeicultura familiar; Certificação de café.

Abstract: The Coffee Certification aims to put the coffee production in the concept of sustainable development, providing advantages regarding ecosystems, soil protection, rational use of inputs, better water use and improve the quality of life of the people involved besides the valuation of output and product, with greater economic return and more social responsibility. The certifications are rules and standards recognized worldwide and thus contribute significantly to the internal organization and to the environmental improvement of the properties. Additionally, it assists in promoting advances in the coffee regions, promoting greater environmental sustainability and enhancement of national coffee production. The goal of this study was to analyze the level of compliance of farmers in some townships of the micro region named Caparao Capixaba, in the state of Espírito Santo, Brazil, regarding the certification process. For data collection, we developed a questionnaire containing 103 questions, relating items such as traceability, varieties, property management, land use, use of fertilizers, phytosanitary protection, irrigation, crop and post-harvest, management of the property waste, welfare and safety of workers, environmental conservation, and administrative and financial management. The results bring the average for each item addressed and pointed out that the family farmers and their properties in the region generally have low level of compliance in integrated production processes regarding coffee certification.

Keywords: Environmental sustainability; Familiar coffee production, Coffee certification.

\footnotetext{
*Autor para correspondência

Recebido para publicação em 07/07/2014; aprovado em 30/03/2015

${ }^{1}$ Biólogo, Pós-graduando em Agroecologia pelo Instituto Federal de Educação, Ciências e Tecnologia do Espírito Santo - Campus Alegre. E-mail: jorge.araujo.santos@hotmail.com

${ }^{2}$ Eng. Agr. D. Sc. Solos e Nutrição de Plantas, Professor D5-3- Instituto Federal de Educação, Ciência e Tecnologia do Espírito Santo - IFES. Caixa Postal: 47. CEP: 29.500-000. Alegre-ES. E-mail: jbpavesi@ifes.edu.br
} 


\section{INTRODUÇÃO}

O Brasil possui quase $20 \%$ de toda área agricultável disponível no planeta, com o maior percentual de área cultivável em relação à área total dos países, com quase $70 \%$ do total do território brasileiro propício à exploração agrícola (NEVES, 2003). De acordo com Henn (2001), o campo brasileiro passou por um processo de modernização, onde a agricultura familiar foi caracterizada como seguimento que resistia à modernização, não conseguindo padrões de qualidade e produtividade por não possuir tecnologia da agricultura avançada. Apesar dessas dificuldades, a agricultura familiar resistiu buscando alternativas para o seu desenvolvimento. Assim vem surgindo várias formas de organização como o associativismo, o cooperativismo e a certificação, que vem fortalecendo quem sobrevive da agricultura familiar.

Países de primeiro mundo visam não só a sustentabilidade socioambiental, mas também a qualidade dos produtos, para isso faz-se necessário que os produtos sejam certificados, e que forneçam informações sobre o processo produtivo e a origem do produto. Assim, Certificação trata-se de um conjunto de normas e padrões técnicos, adotados por instituições privadas ou legislações dos países para a verificação da conformidade (NEVES, 2004).

No mundo todo, critérios como a sustentabilidade são exigidos para a comercialização de produtos, e na cadeia produtiva do café, isso não é diferente. A responsabilidade com a sustentabilidade, questões sociais e ambientais são compromissos cada vez mais assumidos pelo comércio e indústria que procuram levar até o consumidor final, um produto que atenda requisitos no âmbito econômico, social e ambiental.

O café é um dos mais importantes produtos agrícolas de exportação, e uma das principais atividades agrícolas do Brasil, gerando riquezas e divisas para o país, além da função social na geração de empregos diretos e indiretos. Dentre as espécies, o arábica é de grande importância econômica para regiões montanhosas com resultados expressivos de produção (MORAGADO, 2008). A produção na pequena propriedade rural em áreas montanhosas têm custos altos, que dificultam a permanência das famílias no campo, e quem vive dessa atividade, se vê buscando alternativas para agregar valor a sua produção e melhoria na gestão da propriedade. A agricultura familiar é caracterizada por haver proximidade entre os proprietários ou responsáveis pela propriedade, constituindo uma forma de produção social possuindo basicamente três características que são o trabalho, a gestão e a propriedade, ambos ligados à família (PLEIN, 2003).

A Produção Integrada é uma forma de produzir alimentos através de um sistema mais natural, respeitando a capacidade de suporte dos ecossistemas, pois visa reduzir a aplicação de defensivos agrícolas e fazer uso de tecnologias adequadas ao ambiente, diminuindo e eliminando fontes de poluição ambiental geradas pela cultura. Nesse sistema o produtor segue um conjunto de normas objetivando a rastreabilidade de todo o seu processo de produção visando à certificação.

A Certificação de Café tem como intuito inserir a produção de café no conceito de desenvolvimento sustentável, proporcionando vantagens tais como: respeito aos ecossistemas, proteção do solo, racionalidade no uso de insumos, melhor utilização da água, melhoria na qualidade de vida das pessoas envolvidas além da valorização da produção e do produto, com maior retorno econômico e mais responsabilidade social.

Tendo em vista a importância da produção de café como atividade econômica para a agricultura familiar e as exigências crescentes do mercado consumidor, o presente estudo objetivou-se avaliar o nível de conformidade da cafeicultura do Caparaó Capixaba nos processos de produção integrada visando a certificação de café.

\section{MATERIAL E MÉTODOS}

\section{A Região do Caparaó Capixaba}

A Região do Caparaó Capixaba está localizada no sudoeste do Estado do Espírito Santo fazendo divisa com Minas Gerais, compreendendo os municípios de Alegre, Divino de São Lourenço, Dores do Rio Preto, Guaçuí, Ibatiba, Ibitirama, Irupi, Iúna, Muniz Freire e São José do Calçado (Figura 1). Esta região está ligada historicamente à cultura do café, devido às suas condições edafoclimáticas e relevo montanhoso que favorecem a atividade. Mais de $90 \%$ das lavouras de café da região são da espécie Coffea arabica, que responde por cerca de $40 \%$ de toda a produção estadual.

Figura 1. Divisão Regional do Estado do Espírito Santo, tendo a localização da Microrregião do Caparaó

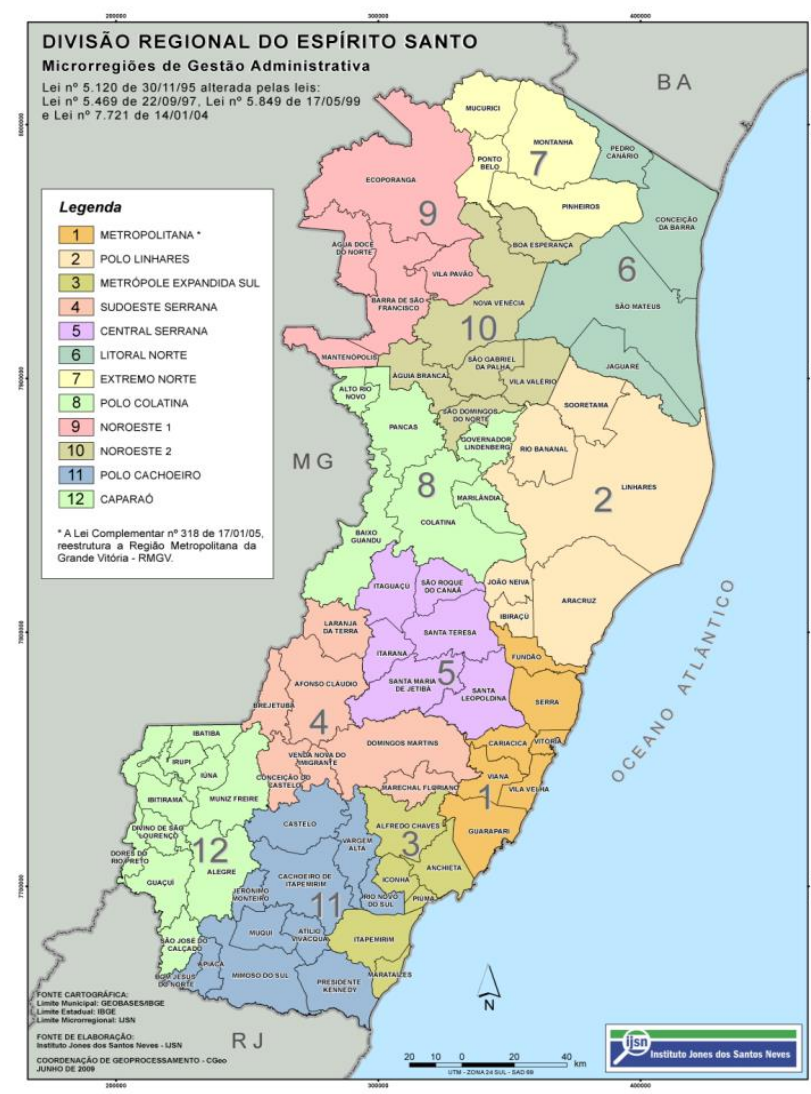

Fonte: Instituto Jones dos Santos Neves, 2014.

A cafeicultura desenvolvida na região do Caparaó Capixaba, expressa importância para os municípios localizados na Microrregião pela dependência econômica (Tabela 1), com área de aproximadamente 80.000 ha e 1 milhão de sacas de produção anual, porém apresenta produtividade média baixa, girando em torno de 13 sacas por hectare (Tabela 2) (IPES, 2005). 
Tabela 1. Dependência econômica do café em propriedades agrícolas de algumas microrregiões do Espírito Santo

\begin{tabular}{cc}
\hline Microrregião & Dependência (\%) \\
\hline Caparaó & 75,8 \\
Central Serrano & 72,9 \\
Serrano & 71,0 \\
Cachoeiro & 69,7 \\
Noroeste & 66,6 \\
Média & 70,9 \\
\hline
\end{tabular}

Fonte: IPES, 2005.

Tabela 2. Área, produção e rendimento do café arábica na microrregião Caparaó no Estado do Espirito Santo

\begin{tabular}{lccccc}
\hline \multirow{2}{*}{ Microrregião } & \multirow{2}{*}{\begin{tabular}{c} 
Áreas das \\
propriedades rurais \\
\cline { 3 - 5 }
\end{tabular}} & ha & Produção (t) & $\begin{array}{c}\text { Área (\%) } \\
\text { Rendimento } \\
\text { (saca/ha) }\end{array}$ & $\begin{array}{c}\text { Área com café } \\
\text { Microrregião Caparaó }\end{array}$ \\
Espírito Santo & $339.406,6$ & 79.280 & $61.164,1$ & 23,36 & 12,9 \\
\hline
\end{tabular}

Fonte: IPES, 2005

A área de estudo compreende os municípios de Alegre, Dores do Rio Preto, Guaçuí e Muniz Freire, além de Jerônimo Monteiro, município vizinho a Região do Caparaó, assim, participa de organismos sociais da região como o Consórcio Intermunicipal e também do Conselho de Desenvolvimento Territorial do Caparaó. Esses cinco municípios possuem comunidades atendidas pelo programa de extensão rural voltado para cafeicultores familiares do Instituto Federal do Espírito Santo (IFES), juntamente com a empresa Caparaó Júnior desde o ano 2009.

Para a realização dessa pesquisa, foi aplicado um questionário junto aos produtores rurais participantes do II Encontro de Cafeicultores do IFES - campus de Alegre, no mês de setembro de 2012. Este encontro teve como tema "Associativismo e Certificação, Bases para a Sustentabilidade da Agricultura Familiar do Caparaó Capixaba". O evento aconteceu no distrito de Rive, município de Alegre, ES, e contou com a participação de 98 produtores rurais, representando 11 comunidades.

O questionário contendo 103 questões relacionou itens de conformidade, agrupados em temas como rastreabilidade, variedades, gerenciamento da propriedade, gestão e uso do solo, emprego de fertilizantes, proteção fitossanitária das plantas, irrigação, colheita e pós-colheita, gestão e resíduos da propriedade, bem estar saúde e segurança de trabalhadores, conservação do meio ambiente, gestão administrativo-financeira, seguindo metodologia descrita por Zambolim (2007).

Os dados coletados foram organizados e sistematizados por meio de tabulação, utilizando planilha eletrônica (Microsoft Office Excel). Os resultados médios de cada item abordado são apresentados em gráficos, seguindo modelo de estatística descritiva (GUERRA; DONARE 1984).

\section{RESULTADOS E DISCUSSÃO}

O processo de certificação envolve os temas: rastreabilidade, variedades, uso do solo e emprego de fertilizante, proteção fitossanitária das plantas, irrigação, colheita e pós-colheita, gestão de resíduos e conservação do meio ambiente na propriedade, saúde e segurança de trabalhadores, gerenciamento e gestão administrativofinanceira da propriedade.

\section{Rastreabilidade}

Rastreabilidade significa a capacidade de encontrar o histórico do processo de produção e de localização ou utilização de um produto por meio de identificação registrada, possibilitando responder ao interesse dos consumidores sobre a segurança do café produzido em termos de qualidade e conscientização da necessidade de preservar o meio ambiente, o bem-estar dos trabalhadores e da sociedade de um modo geral (ZAMBOLIM et al., 2003). Para o bom desenvolvimento e organização das atividades em uma propriedade rural, faz-se necessário o planejamento e controle das atividades, mantendo-se registros e controles das atividades, para possibilitar o rastreamento de todas as etapas do processo de produção integrada.

Nas propriedades analisadas nessa pesquisa, 47\% dos produtores não possuem nenhum tipo de treinamento em certificação de café, porém, é possível perceber que 59\% dos produtores participam de processos associativos. No que se refere aos registros de atividades, $70 \%$ dos produtores não realizam anotações ou registros de dados ou atividades desenvolvidas, $75 \%$ não possuem mapa da propriedade e $73 \%$ não identificam as lavouras com placas (Figura 2).

Nas ações de monitoramento de chuvas e registro de temperatura na propriedade, $86 \%$ dos produtores não monitora a quantidade de chuvas e $94 \%$ não registra a temperatura na propriedade. Nos processos de registros de temperatura no secador e separação dos lotes de cafés, $77 \%$ dos produtores entrevistados não registram a temperatura de secagem do café no secador e $63 \%$ não separam os lotes de cafés. 
Figura 2. Adoção das exigências para certificação de café nas atividades de Rastreabilidade por cafeicultores da região do Caparaó Capixaba. Espirito Santo. Brasil

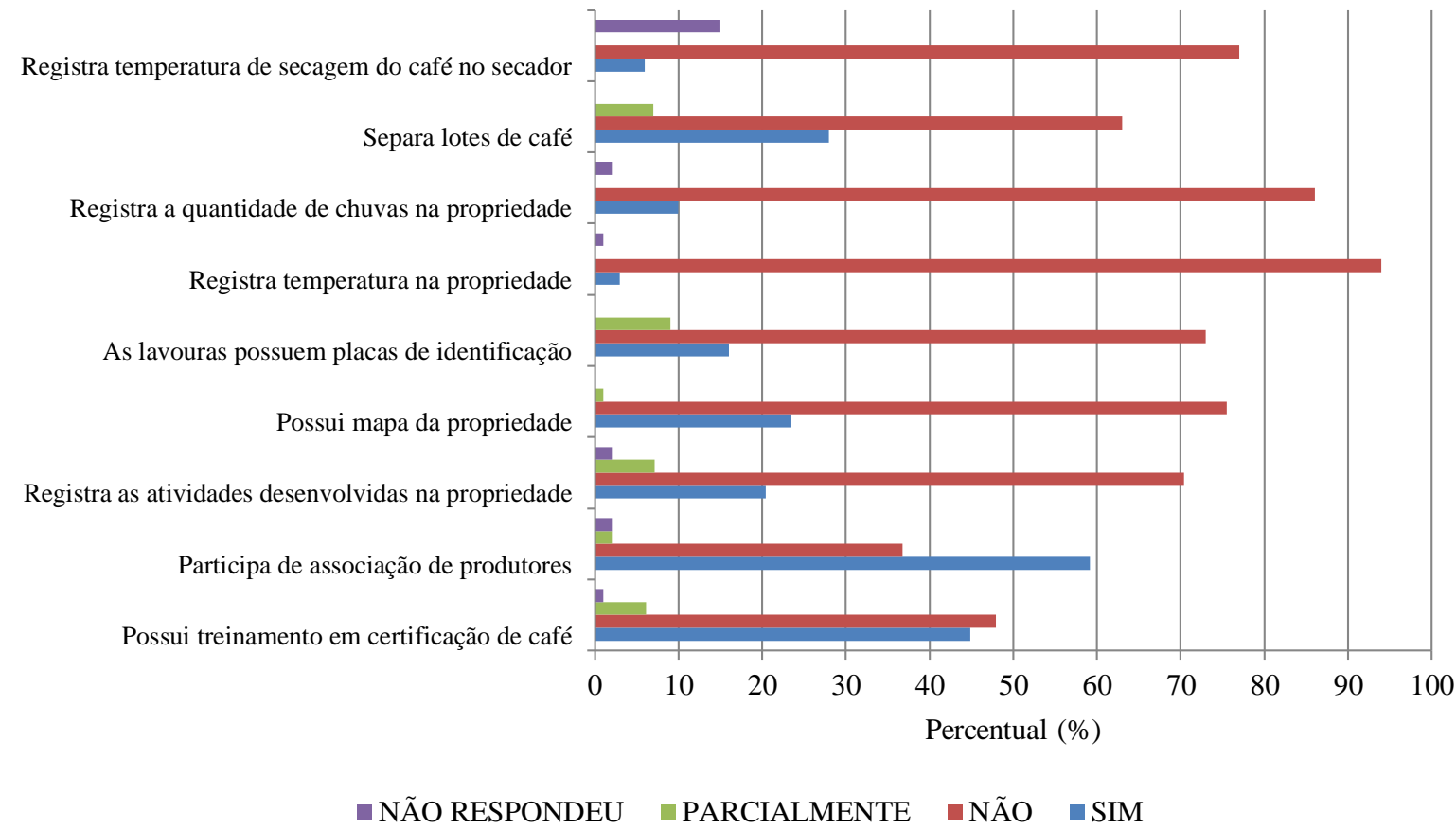

\section{Variedades}

A qualidade da produção de café depende de um conjunto de características organolépticas do grão ou da bebida, desta forma fatores como genética da variedade, clima, topografia, pragas e doenças, propriedades do solo, aplicação de adubos e defensivos, bem como operações de colheita, secagem, beneficiamento e armazenamento influenciam diretamente no resultado da qualidade do produto final (MALAVOLTA, 2000).

Em relação às variedades de café escolhidas para o plantio, $52 \%$ dos produtores conhecem e utilizam de variedades indicadas para a região, resistentes ou tolerantes a doenças, sendo que $71 \%$ adquirem mudas em viveiros registrados. Com relação às notas fiscais e certificados fitossanitários das mudas, mais de $68 \%$ das propriedades não solicitam esses documentos e $75 \%$ das propriedades não possuem certificado fitossanitário das mudas. Quanto ao plantio, 65\% dos produtores conhecem a variedade plantada em cada talhão e com relação a recomendação técnica, 72\% dos produtores seguem as recomendações que permitem a adequada proteção do solo, item de conformidade exigido na certificação de café (Figura 3).

Figura 3. Adoção das exigências para certificação de café para atividades em relação as variedades cultivadas por cafeicultores da região do Caparaó Capixaba. Espirito Santo. Brasil

Segue recomendação técnica para plantio das mudas

Conhece as variedades plantadas em cada talhão

Possui certificadas fitossanitários das mudas

Arquiva notas fiscas das mudas adquiridas

Adquire mudas em viveiros registrados

Conhece variedades indicadas para região

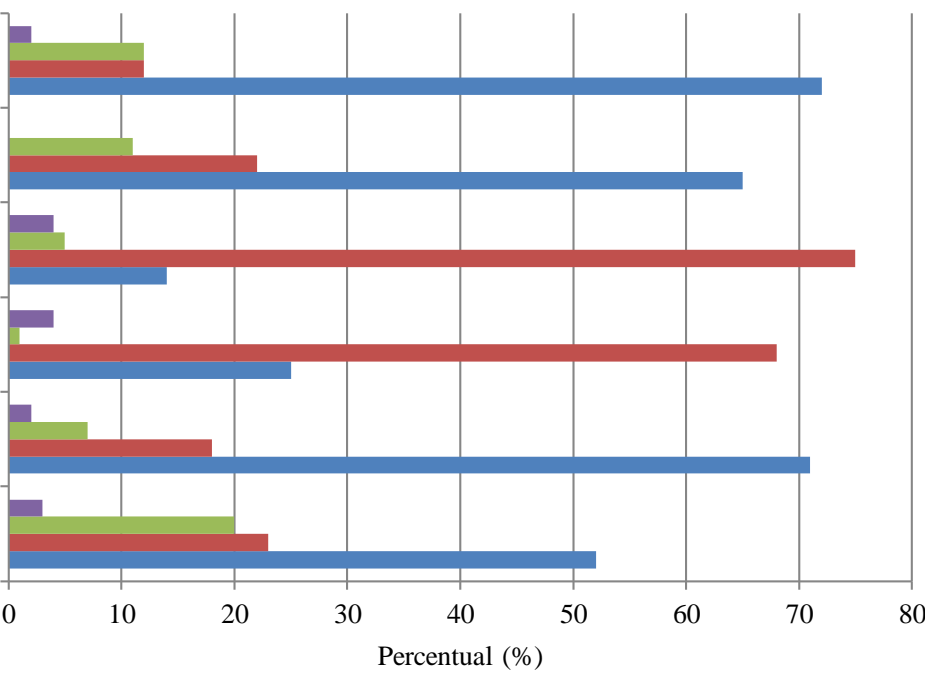

$\square$ NÃO RESPONDEU $\square$ PARCIALMENTE $\square$ NÃO $\square$ SIM 


\section{Uso do solo e emprego de fertilizantes}

A aplicação de práticas que objetivam a proteção da superfície do solo pode contribuir para melhorar a qualidade física e impedir a compactação superficial, diminuindo assim os processos erosivos. Nos diferentes métodos de controle das plantas daninhas utilizados em lavouras, o manejo adequado da cobertura vegetal, pode, ainda, melhorar a qualidade química do solo, com fornecimento de matéria orgânica (ALCÂNTARA, 1997).

Com relação ao uso do solo, $83 \%$ dos produtores utilizam de técnicas de controle da vegetação sendo a mais utilizada a roçadeira motorizada devido à facilidade em seu manuseio. Percebe-se também que $52 \%$ das propriedades possuem áreas de APP identificadas e $67 \%$ dos produtores utilizam o herbicida de forma racional. Com relação ao manejo integrado do mato, 58\% realizam este tipo de procedimento. Em relação ao armazenamento dos fertilizantes, 55\% possuem local apropriado e 77\% estocam os fertilizantes separados de alimentos e, ou outros insumos. Quanto sua aplicação, nota-se que $87 \%$ realizam a adubação com base na análise de solo, sendo $89 \%$ indicado por profissionais que assinam a recomendação. Isso se deve a facilidade de contato com empresas e órgãos de assistência técnica. Todos esses fatores contribuem para o processo de certificação de café. Nota-se que $53 \%$ dos produtores arquivam informações das adubações de safras anteriores (Figura 4).

Para Zambolim (2007), é necessário realizar análises de solos e folhas da cultura em exploração por gleba. Com base nessas análises e nos níveis críticos de cada nutriente, será recomendada a quantidade de cada nutriente a ser fornecido. Sendo assim, a conservação do solo e seu equilíbrio bem como a melhoria da sua fertilidade são componentes essenciais do sistema de produção, além de contribuir na tolerância ao ataque de pragas e doenças na cultura.

Figura 04. Adoção das exigências para certificação de café nas atividades relacionadas ao uso do solo e emprego de fertilizantes por cafeicultores da região do Caparaó Capixaba. Espirito Santo. Brasil

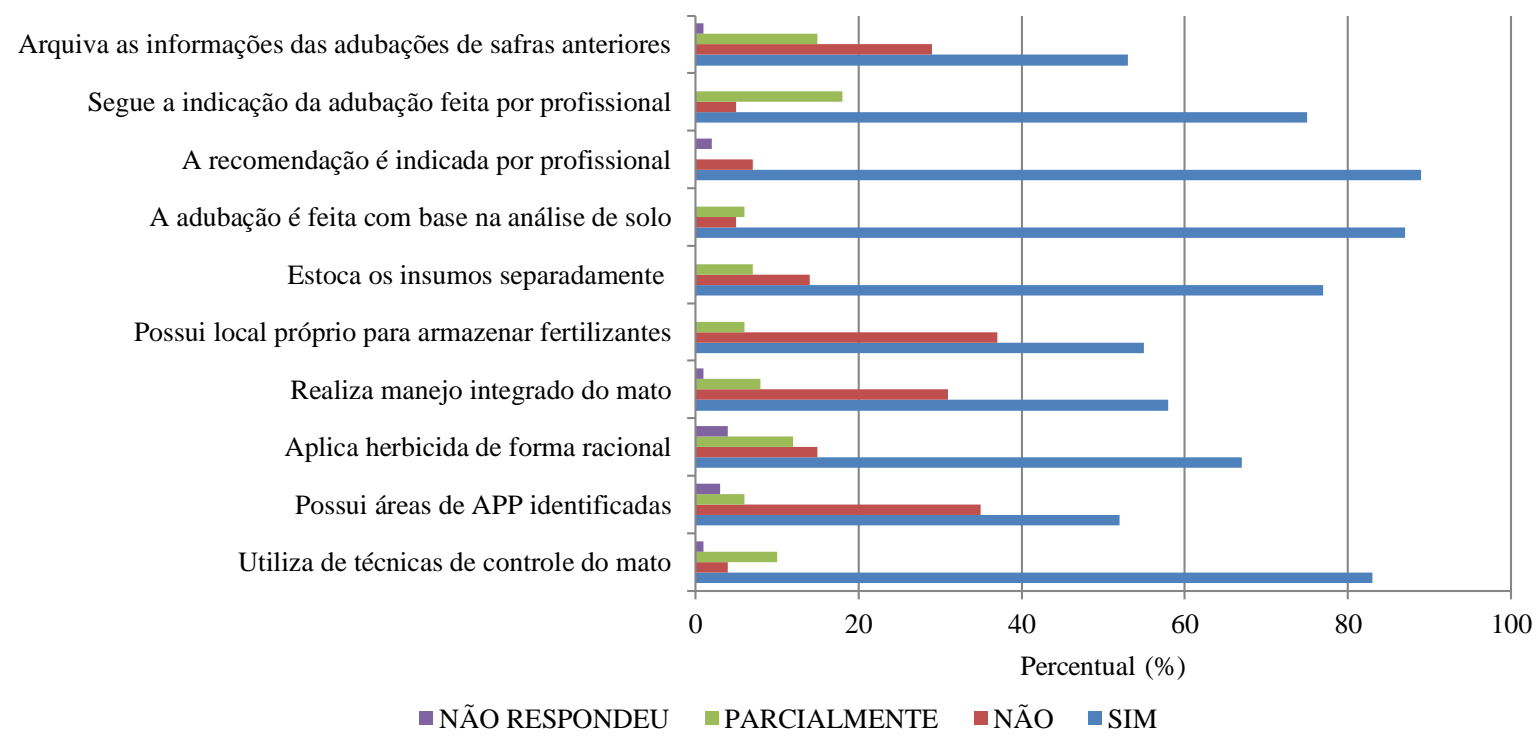

\section{Proteção fitossanitária das plantas}

No controle fitossanitário, podem-se integrar diferentes métodos de controle de insetos, como o Manejo Integrado de Pragas (MIP), que diminui a dependência dos defensivos agrícolas, valorizando o controle biológico e o uso de plantas resistentes às pragas (LIMA et al., 2003).

Para a certificação de café, faz-se necessário a utilização de produtos fitossanitários que sejam registrados para a cultura, mediante receituário técnico e legislação vigente. Percebe-se com os dados obtidos na pesquisa que $44 \%$ das propriedades não realizam o controle fitossanitário das plantas de forma correta, destacando-se com maiores percentuais a falta de registros de controle dos fitossanitários $77 \%$, e a falta de sinalização da área de aplicação, $82 \%$. Segundo SENAI (2004), a comprovação da isenção de contaminação do produto por perigos químicos, como os resíduos de defensivos agrícolas, torna-se requisito importante, para quem deseja ingressar no mercado internacional.

Nota-se também que $65 \%$ dos aplicadores de produtos fitossanitários não possuem treinamento, $63 \%$ manuseiam esses produtos em locais inadequados e $48 \%$ não sabem se os produtos utilizados são registrados para o café no Ministério da Agricultura, $47 \%$ das propriedades não recolhem embalagens vazias.

Destaca-se também que $67 \%$ dos entrevistados respeitam os intervalos de carência recomendados após a aplicação dos produtos fitossanitários e $46 \%$ realizam algum tipo de monitoramento de pragas e doenças (Figura 5). 
Figura 5. Adoção das exigências para certificação de café nas atividades de Proteção fitossanitária das plantas por cafeicultores da região do Caparaó Capixaba. Espirito Santo. Brasil

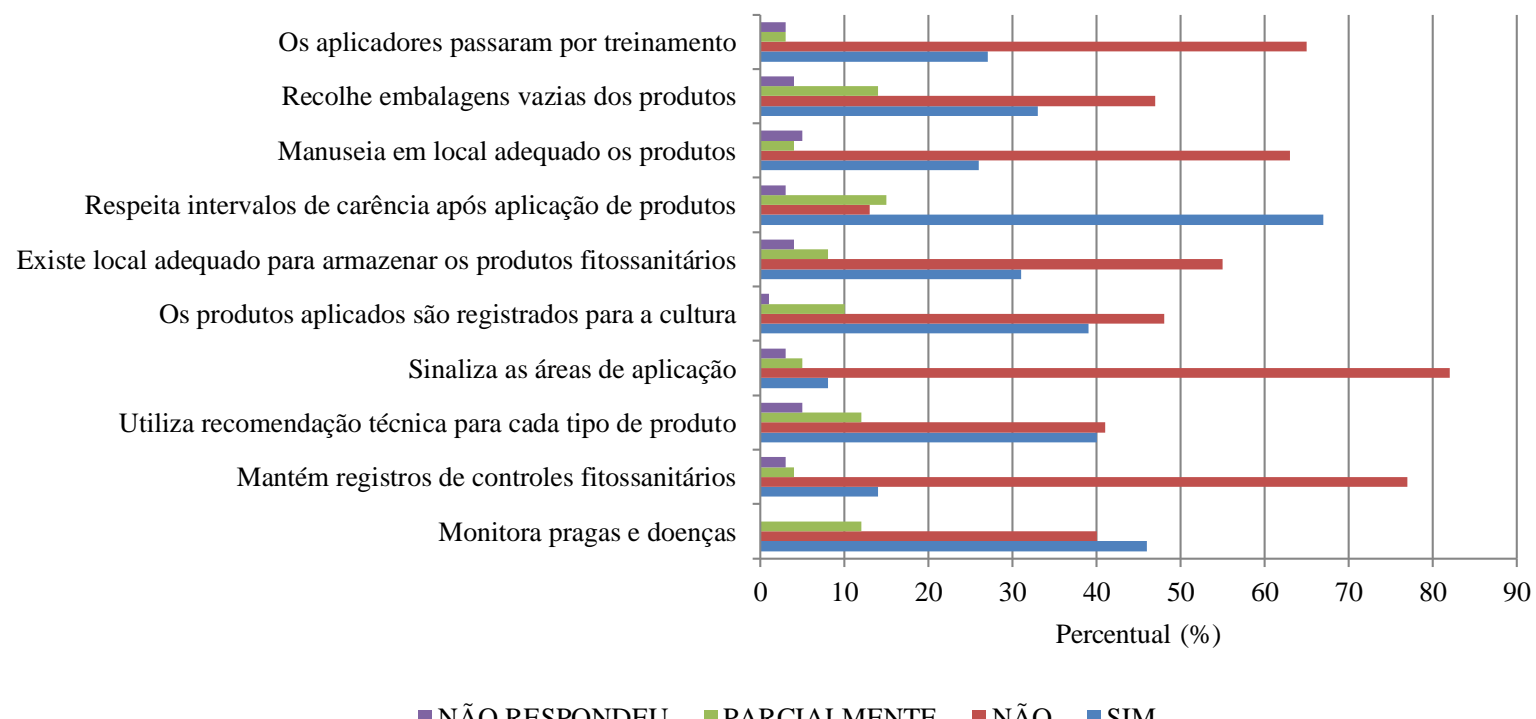

NÃO RESPONDEU PARCIALMENTE NÃO NIM

\section{IRRIGAÇ̃̃O}

Segundo Zambolim (2007) a irrigação não deve ser considerada isoladamente, mas sim como um conjunto de técnicas utilizadas para garantir a produção econômica de determinada cultura.

Com referência à irrigação da cafeicultura, Mendonça (2000) relata que seja feito um planejamento, aliado a um nível tecnológico eficiente, para que a atividade seja rentável e para que as técnicas de irrigação empregadas possam resultar em maior racionalidade no uso da energia e da água.

Para exploração comercial da cultura do café, o regime de chuvas considerado ideal está em torno de 1.200 $\mathrm{mm}$ e $1.800 \mathrm{~mm}$ anuais, sendo importante que esta precipitação esteja distribuída de forma que atinja os períodos vegetativos e de frutificação.

Percebe-se na pesquisa que $80 \%$ das propriedades não utilizam sistema de irrigação, isso se deve ao fato de que a maioria das lavouras se encontra em regiões com precipitações anuais adequadas ao bom desenvolvimento da cultura. Percebe-se que nas propriedades que utilizam irrigação, 74\% não conhecem outorga de água e 51\% não dispõem de sistema de irrigação eficiente, $48 \%$ não extraem a água de fontes renováveis (Figura 6).

Figura 6. Adoção das exigências para certificação de café nas atividades de Irrigação por cafeicultores da região do Caparaó Capixaba. Espirito Santo. Brasil

A água de irrigação é extraída de fontes renováveis

O sistema de irrigação empregado é eficiente

Conhece outorga de água

Possui lavoura com irrigação

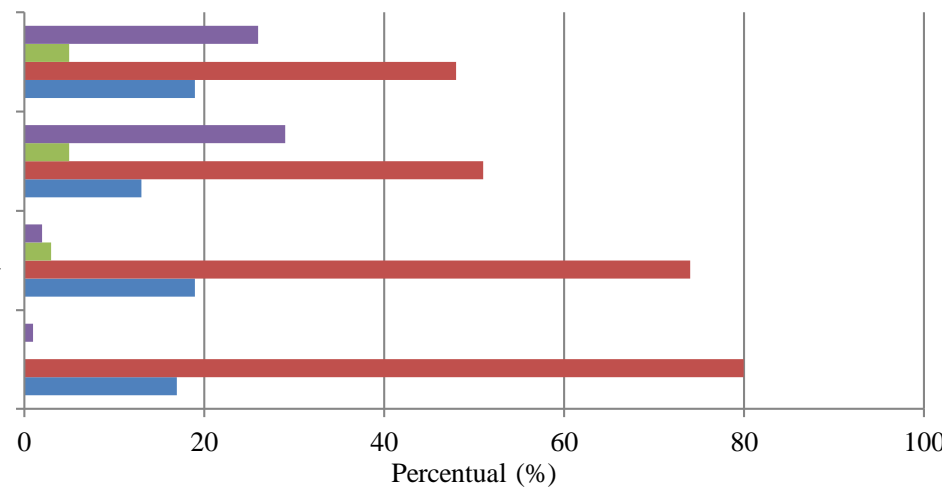

nÃO RESPONDEU $\square$ PARCIALMENTE $\square$ NÃO $\square$ SIM

\section{Colheita e pós-colheita}

A colheita é a operação mais importante, levando em conta seu impacto econômico social na lavoura cafeeira, pois grande parte do custo de produção do café é derivada da colheita, utilizando a maior parcela da mão de obra e influenciando diretamente na qualidade final do produto (MATIELLO et al., 2002).
Dados da pesquisa revelam que $56 \%$ dos produtores não transportam o café no mesmo dia que foi colhido para o terreiro ou secador, $47 \%$ não separa o tipo de café durante a secagem ou armazenamento e $67 \%$ não monitoram a umidade do café durante a secagem, por não disporem na propriedade ou comunidade, aparelho para aferir a umidade durante o processo de secagem. Neste sentido faz-se necessário por parte dos produtores ou das comunidades a aquisição de 
aparelho para aferir a umidade final dos grãos, garantindo não só a manutenção da qualidade do café enquanto armazenado, como no beneficiamento e comercialização. O controle da umidade dos grãos deve ser uma preocupação permanente para manutenção da qualidade do café.

No processo de certificação, alguns cuidados como a identificação e separação dos tipos de cafés e lotes são necessários para identificar a qualidade e rastreabilidade dos lotes até a gleba que foi colhida. Desta forma, nota-se que
$47 \%$ dos produtores não têm este tipo de cuidado na armazenagem.

Com relação à higienização dos equipamentos, dos produtores entrevistados, 53\% realizam esse procedimento, $64 \%$ mantêm as tulhas limpas e $70 \%$ armazenam lubrificantes e combustíveis em locais adequados e separados do café de sacaria. Quanto à água utilizada no processo de separação, descascamento e, ou, despolpamento, $66 \%$ das propriedades realizam tratamento ou depositam as águas em local adequado (Figura 7).

Figura7. Adoção das exigências para certificação de café nas atividades de Colheita e Pós-colheita por cafeicultores da região do Caparaó Capixaba. Espirito Santo. Brasil

Existe proteção contra entrada de animais nas áreas de secagem

Lubrificantes e combustíveis são aramzenados separados

A água utilizada no beneficiamento é tratada

As tulhas são limpas antes do armazenamento

É verificada a umidade do café durante a secagem

O café colhido vai para o terreiro no mesmo dia

Separa o tipo de café na secagem e armazenamento

Higieniza equipamentos antes do contato com o café colhido

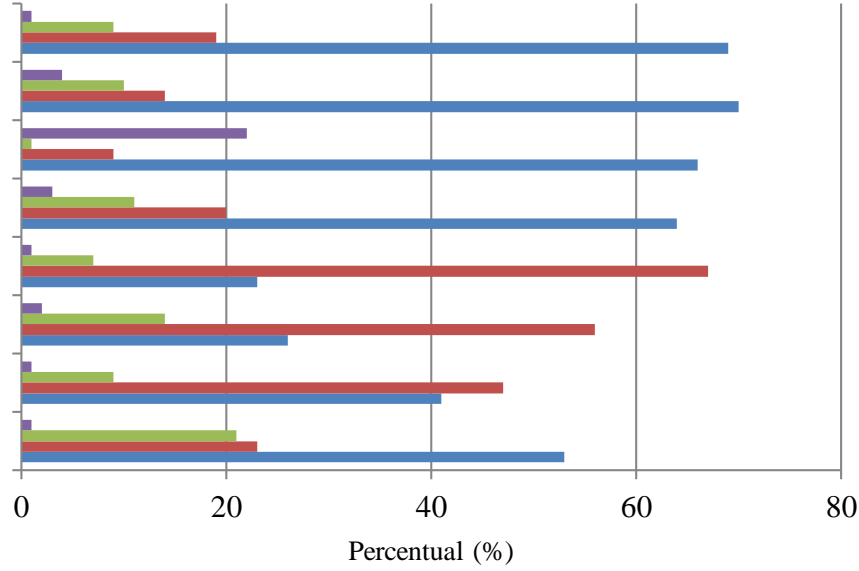

\section{nÃO RESPONDEU $\square$ PARCIALMENTE $\square$ NÃO $\square$ SIM}

Gestão de resíduos e conservação do meio ambiente na propriedade

Para a produção integrada é de grande importância que áreas naturais sejam preservadas nas propriedades, uma vez que estas podem proporcionar benefícios com relação à proteção dos recursos hídricos, conservação da biodiversidade e manutenção das características climáticas (OLIVEIRA, 1989).

Nas ações de gestão de resíduos e conservação do meio ambiente na propriedade, observa-se que $90 \%$ dos produtores pesquisados nunca utilizaram o fogo na limpeza de pastos ou áreas cultivadas e $80 \%$ preservam e protegem suas nascentes e, ou, córregos. Nota-se que $45 \%$ dos produtores trabalham para aumentar a biodiversidade na propriedade.

Percebe-se que $56 \%$ das propriedades direcionam os resíduos gerados em locais adequados, como por exemplo, o esgoto sanitário em fossa séptica. Nota-se que 69\% utilizam os resíduos orgânicos de café como adubo na lavoura. Entretanto, 58\% não possuem local adequado a disposição de resíduos sólidos (lixo) sendo necessário a construção de locais específicos e adequados (Figura 8).

Figura 8. Adoção das exigências para certificação de café nas atividades de Gestão de resíduos e conservação do meio ambiente na propriedade por cafeicultores da região do Caparaó Capixaba. Espirito Santo. Brasil

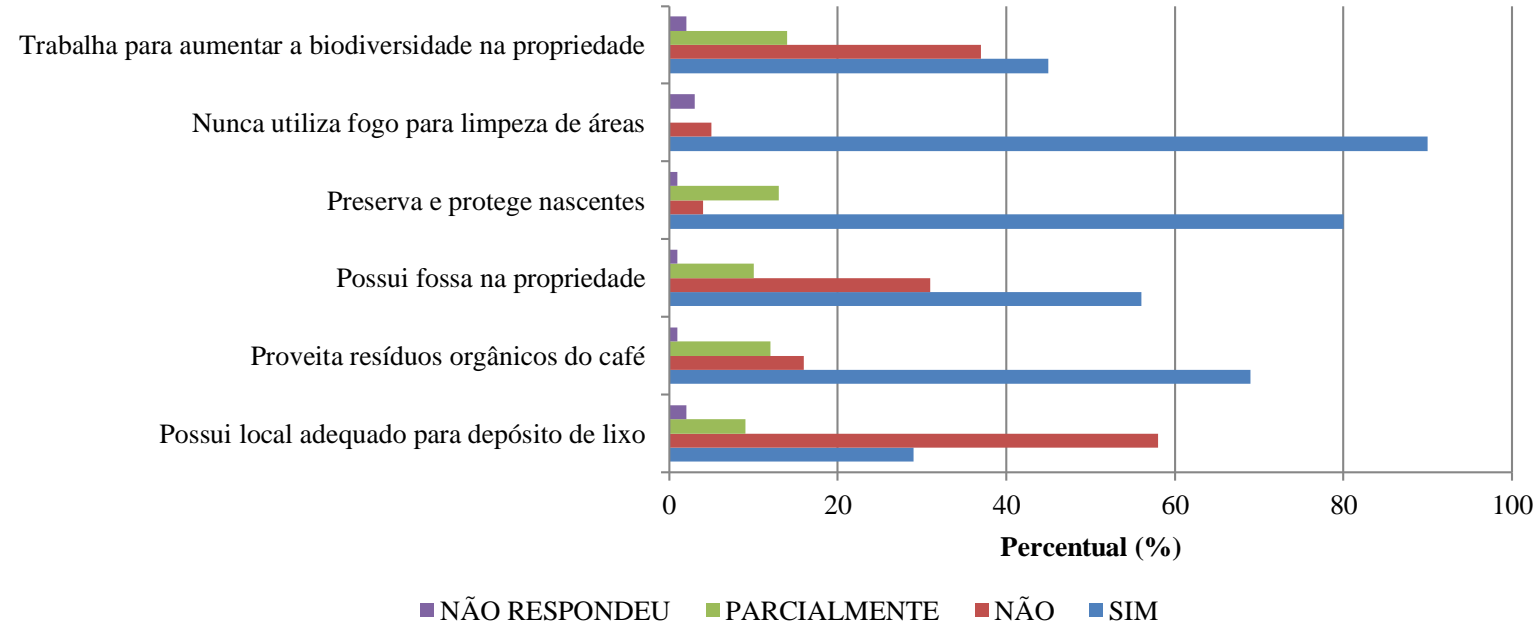




\section{Saúde e segurança de trabalhadores}

A Saúde e Segurança dos Trabalhadores é outro tema relevante e de grande importância nos processos de produção integrada. Percebe-se que a maioria das propriedades não atende a ações que preservem a saúde dos trabalhadores e de seus familiares.

Nota-se que $62 \%$ dos trabalhadores não possuem treinamento de aplicação de produtos fitossanitários e que $79 \%$ dos trabalhadores das propriedades não possuem treinamento em primeiros socorros. Entretanto percebe-se que $38 \%$ dos trabalhadores utilizam algum tipo de EPI, e $75 \%$ das propriedades não possuem caixas de primeiros socorros.
Neste sentido, é necessário capacitação para realização de atividades que oferecem riscos à saúde, bem como treinamentos para prestar os primeiros socorros, se for o caso.

Com relação à identificação das áreas de perigos, $70 \%$ das propriedades não identificam as áreas de riscos ou perigo, e $81 \%$ não analisam a água que é consumida na propriedade.

Percebe-se que os produtores têm cuidados relacionado a regularização dos empregados, onde $50 \%$ das propriedades atendem a legislação trabalhista específica para a atividade (Figura 9).

Figura 9. Adoção das exigências para certificação de café nas atividades de Saúde e segurança de trabalhadores por cafeicultores da região do Caparaó Capixaba. Espirito Santo. Brasil

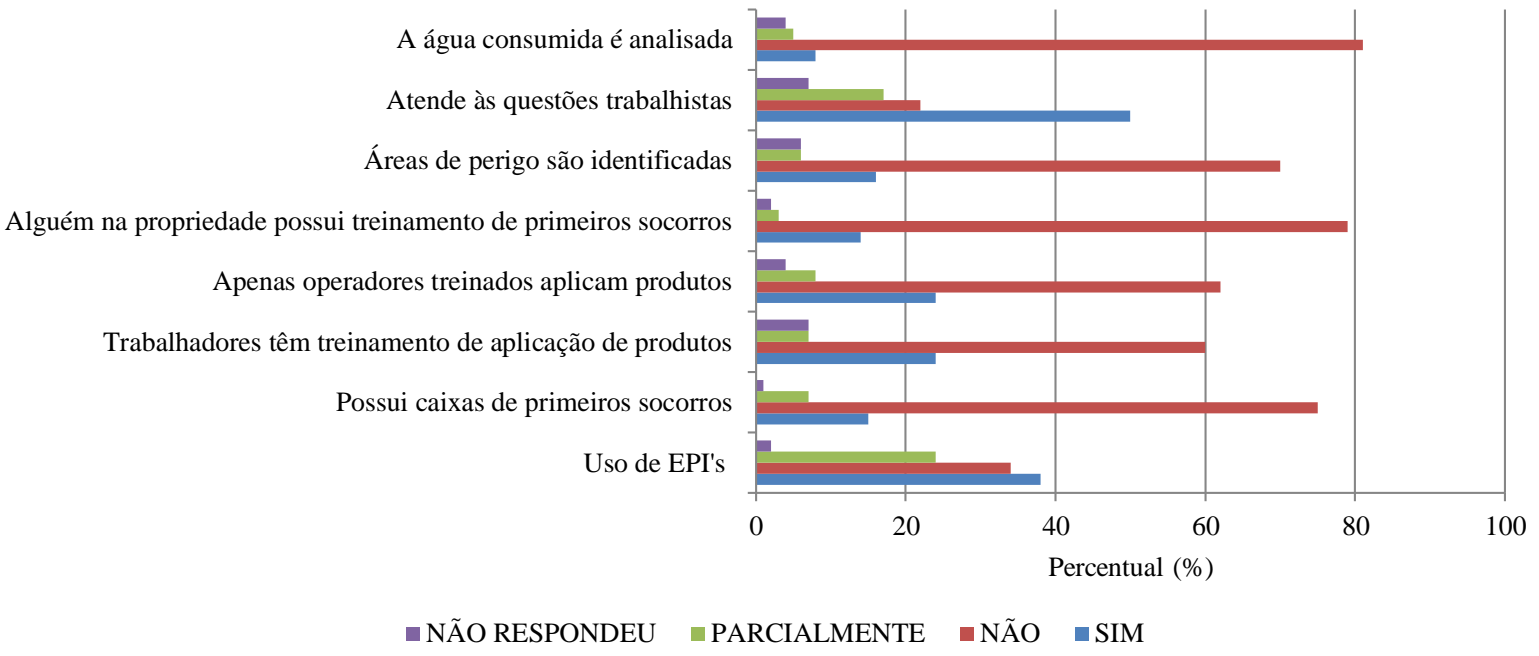

\section{Gerenciamento e gestão administrativo-financeira da propriedade}

Cafeicultores assim como técnicos que prestam assistência, devem preocupar-se continuamente com os custos relacionados às diversas práticas utilizadas na lavoura cafeeira, com o objetivo de escolher as alternativas mais econômicas que revelem a melhor relação custo/benefício (MATIELLO et al., 2010).

Segundo Andrade (1999), no processo administrativo de uma propriedade rural, para que se alcancem os objetivos, deve-se passar por planejamento, organização, direção e controle, ocorrendo nos níveis estratégicos, como o gerencial e operacional.
Quanto ao gerenciamento e a gestão administrativofinanceira da propriedade, verifica-se uma tendência em registrar os custos da lavoura, onde 38\% dos agricultores realizam algum tipo de registro. Em relação aos registros de despesas e receitas da propriedade, $37 \%$ não realizam nenhum tipo de registro.

Destaca-se no processo de gerenciamento da propriedade informação referente a legislação ambiental, onde $52 \%$ dos produtores entrevistados tem conhecimento sobre legislação ambiental vigente e $61 \%$ obedecem a legislação ambiental (Figura 10).

Figura 10. Adoção das exigências para certificação de café de atividades de gerenciamento e gestão administrativo-financeira da propriedade por cafeicultores da região do Caparaó Capixaba. Espirito Santo. Brasil

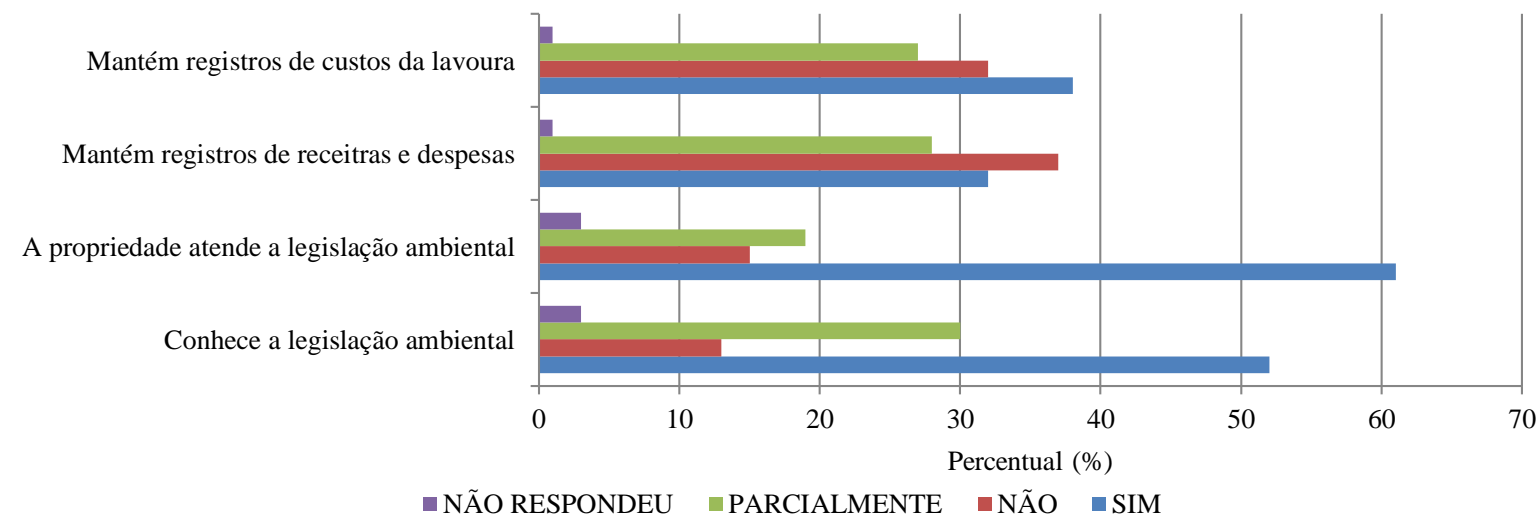


Índices de conformidade dos cafeicultores da Região do Caparaó capixaba

A Figura 11 apresenta os nove temas dispostos em um diagrama onde os índices de conformidade (média) já são adotados pelos cafeicultores da região do Caparaó Capixaba. Nele destaca-se o baixo nível de adoção de práticas de conformidade para a certificação. Em cinco dos nove temas que agrupam itens de conformidade, as repostas positivas (sim) não atingem sequer a $50 \%$, ou seja, há grande limitação dos produtores para compreenderem e/ou adotarem práticas necessárias à certificação, tais como irrigação, rastreabilidade, proteção fitossanitária, situação trabalhista, gerenciamento e gestão, irrigação e rastreabilidade.

Com relação aos resultados observados para a irrigação, não se pode concluir que o comportamento do gráfico constitui empecilho à certificação, uma vez que $80 \%$ das propriedades não utilizam sistema de irrigação, e que precipitações anuais adequadas podem satisfazer as necessidades das lavouras para média ou alta produtividade. Esse quadro, entretanto, pode se agravar na medida em que as condições climáticas se tornem desfavoráveis, impactando a base sustentável de produção racional de café.

Os temas variedades, conservação do meio ambiente, colheita e pós-colheita são compreendidos e ou adotados de forma insatisfatória (abaixo de 60\%), enquanto que o uso do solo e adubação constitui o único tema cuja média de respostas atinge um valor considerado bom (acima de 70\% de respostas positivas)

Diante do exposto, os resultados obtidos nesta pesquisa mostram que os cafeicultores da região do Caparaó Capixaba necessitam de capacitação e de um modelo de assistência técnica mais consistente, focados no atendimento a um mercado cada vez mais exigente e que tem balizado os procedimentos de produção agrícola respeitando aspectos sociais, ambientais e econômicos.

Figura 11. Índices de conformidade dos cafeicultores da região do Caparaó Capixaba com as exigências da certificação. Espirito Santo. Brasil

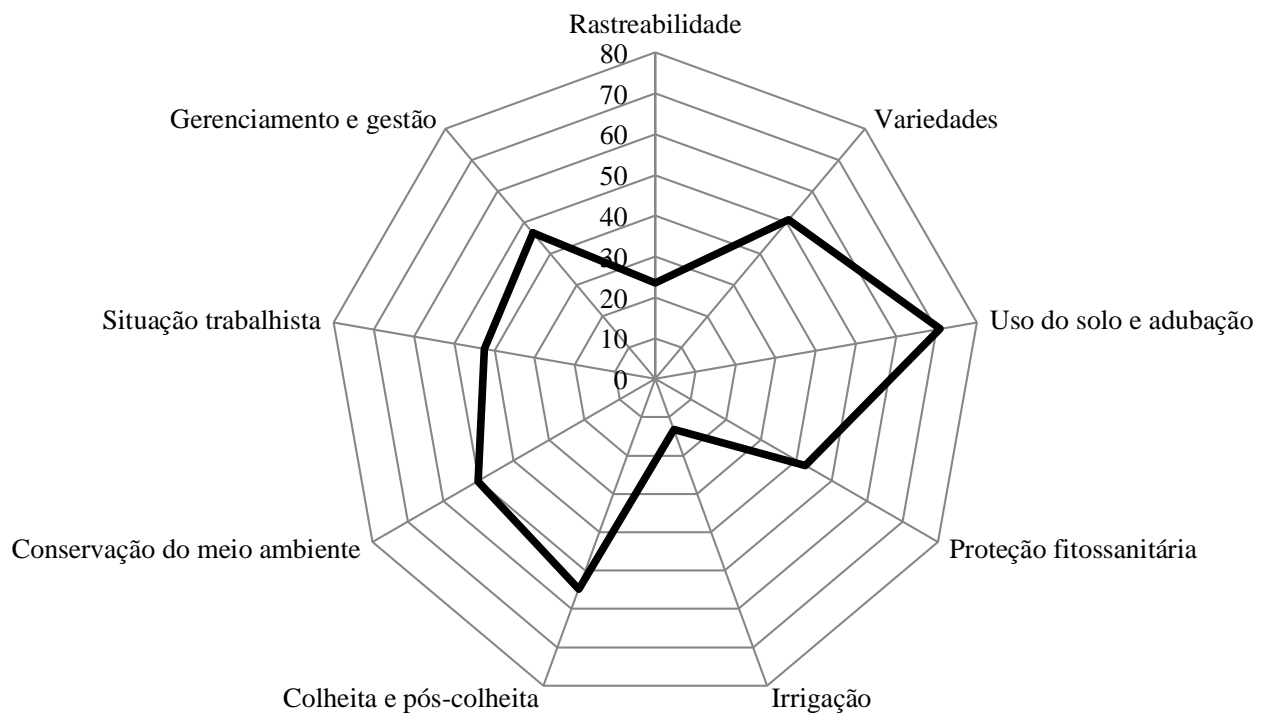

\section{CONCLUSÕES}

Os cafeicultores familiares e suas propriedades na região do Caparaó Capixaba apresentam, de modo geral, baixo nível de conformidade nos processos de produção integrada visando certificação de café.

As maiores limitações são verificadas quanto à compreensão e/ou adoção de práticas relacionadas ao gerenciamento e gestão da propriedade, à rastreabilidade, à proteção fitossanitária e à situação trabalhista.

\section{REFERÊNCIAS}

ALCÂNTARA, E. N. de. Efeito de diferentes métodos de controle de plantas daninhas na cultura do cafeeiro (Coffea arabica L.) sobre a qualidade de um Latossolo Roxo distrófico. 1997. 133 f. Tese (Doutorado em Fitotecnia) - Universidade Federal de Lavras, Lavras, 1997.

ANDRADE, J. G. de. Gerenciando a fazenda cafeeira. Lavras: UFLA/FAEPE, 1999. 89 p. (Textos acadêmicos).
GUERRA, M. J.; DONARE, D. Estatística indutiva: Teoria e Aplicações. São Paulo: Livraria Ciência e Tecnologia, 1984.

HENN, I.A. et. Al. (Orgs). Programa dos agentes comunitários de desenvolvimento e crédito: proposta de articulação e formação na perspectiva da agricultura familiar. Francisco Beltrão: Infocos, 2001.

IJSN-Instituto Jones dos Santos Neves. Divisão Regional do Espírito Santo. 2014. Disponível em:

http://www.ijsn.es.gov.br/Sitio/index.php?option=com_wrapp er\&view=wrapper\&Itemid=109. Acesso em: 16 abr. 2014 .

LIMA, E. R.; AMBROGI, B. G.; COSTA, F. G.; SARAIVA, R. M. Emprego de semioquímicos no manejo de pragas do café. In: ZAMBOLIM, L. Produção integrada de café. Viçosa: UFV, 2003. p. 7-66. 
MALAVOLTA, E. História do café no Brasil: agronomia, agricultura e comercialização. São Paulo: Ceres, 2000. 464 p.

MATIELlO, J. B. et al. Cultura de café no Brasil: manual de recomendações. Rio de Janeiro - RJ e Varginha - MG: Edição - Ministério da Agricultura, Pecuária e Abastecimento - SARC/PROCAFÉ - SPAE/DECAF, Fundação PROCAFÉ, março de 2010.

MATIELlO, J. B. et al. Cultura do café no Brasil: novo manual de recomendações. Rio de Janeiro - RJ e Varginha MG: Edição - Ministério da Agricultura, Pecuária e Abastecimento - SARC/PROCAFÉ - SPAE/DECAF, Fundação PROCAFÉ, março de 2002.

MENDONÇA, F. C. Evolução dos custos e avaliação econômica de sistemas de irrigação utilizados na cafeicultura. In: SIMPÓSIO BRASILEIRO DE PESQUISA EM CAFEICULTURA IRRIGADA, 3., 2000, Araguarí, MG Anais... Araguari: [s.n.], 2000.

MORAGAdO, A. A. M. Produção de Café no Brasil - Uma Visão Produção Arábica e Robusta. 2008.

Disponível em: http://www.revistacafeicultura.com.br/index.php?tipo=ler\&m at $=25460$. Acesso em: 16 maio. 2014.

NEVES, M. C. P. Certificação: garantia da qualidade dos produtos orgânicos, In: PRINCÍPIOS e práticas agroecológicas aplicadas à agricultura orgânica. Brasília : Embrapa SCT, 2004.
NEVES, M.F.; CHADDAD, F.R.; LAZZARINI, S.G. Gestão de Negócios em Alimentos. São Paulo: Pioneira Thomson Learning, 2003.

OLIVEIRA, F. A. Produção e qualidade da água em bacias hidrográficas contendo diferentes coberturas vegetais na Região de Agudos, São Paulo. 1989. 81 f. Dissertação (Mestrado) Escola Superior de Agricultura de Luiz de Queiroz, Piracicaba, 1989.

PLEIN, C.; SCHNEIDER, S. Agricultura familiar e Mercantilização. In: Agronegócio e Desenvolvimento Sustentável. Francisco Beltrão, 2003.

SENAI. Manual de segurança e qualidade para a cultura do café. Brasília, DF, 2004. 83 p. (Serie qualidade e segurança dos alimentos).

ZAMBOLIM, L. Boas práticas agrícolas na produção de café. Viçosa: UFV, DPFP, 234 p.

ZAMBOLIM, Laércio. Certificação de café. Viçosa: Ufv, 2007. 245 p.

ZAMBOLIM, L; ZAMBOLIM, E. M. Subsídios para a Produção Integrada de Café, cap. 3 in: Certificação de Café(ZAMBOLIM, L. ed). p. 25 a 97, 2007).

ZAMBOLIM, L.; VALE, F. X. R. do; ZAMBOLIM, E. M. Produção integrada do cafeeiro: manejo de doenças. In: ZAMBOLIM, L. Produção integrada de café. Viçosa: UFV, 2003. p. 443-508. 